www.jmscr.igmpublication.org

Impact Factor 5.244

Index Copernicus Value: 5.88

ISSN (e)-2347-176x ISSN (p) 2455-0450

crossref DOI:_http://dx.doi.org/10.18535/jmscr/v4i3.31

Journal Of Medical Science And Clinical Research

IGM Publication

An Official Publication of IGM Publication

\title{
Diurnal Variation of Peak Expiratory Flow Rate in Healthy Young Adults of North East of India
}

Authors

\author{
Wasima Jahan*1, Pranjal Bhuyan $^{2}$, Rwitusmita Bharali ${ }^{3}$ \\ ${ }^{1}$ Professor of Physiology, Assam Medical College, Dibrugarh \\ ${ }^{2}$ Demonstrator of Physiology, Guwahati Medical College, Guwahati \\ ${ }^{3}$ Demonstrator of Physiology, Assam Medical College, Dibrugarh \\ Corresponding Author
}

Wasima Jahan

Professor of Physiology, Assam Medical College, Dibrugarh-786002

Email:-wasimajahan@gmail.comPhno-9435031453

\begin{abstract}
PEF measurement is a simple and easy procedure to evaluate and assess the degree of 24hrs variation (circadian) in lung function. Thus this study was undertaken to study the diurnal variation in peak expiratory flow (PEF) in 60 healthy non-smoking adults of Northeast, in the age group between 18-24 years. The PEFR (L/min) was measured with mini Wright's peak flow meter for three times a day, morning, afternoon and evening. The diurnal variation was observed with lowest values in the morning followed by progressive rise peaking in the evening. Diurnal variation for individual subject was calculated by using amplitude percent mean (A\%M). We conclude that a definite pattern of diurnal variation in PEF is seen in healthy population and its knowledge is important for meaningful interpretation of PEF recordings in disease condition.

Key words: Peak expiratory flow, diurnal variation
\end{abstract}

\section{INTRODUCTION}

The Peak Expiratory Flow Rate (PEFR) is commonly used to study the airflow as a marker of asthma control. It has been widely used in clinical practice and in asthma research. Variability in the airway function during 24 hours, observed as a characteristic diurnal variation in PEFR has been observed not only in asthmatics but in majority of healthy people also. The PEFR measurement is easy to perform and can be carried out repeatedly with simple equipment. No adequate data is available for diurnal variability in normal healthy individuals of the North East.
Hence the study was undertaken to find out the mean diurnal variation of PEF and evaluate the pattern of diurnal variation of PEF in normal young healthy adults of North East region of India.

Materials and Methods:- PEFR was recorded in 60 healthy non smoking, medical students of age group between 18 - 24 years, of both sexes $(\mathrm{M}=30, \mathrm{~F}=30)$ using mini-Wright's peak flow meters. A thorough history and relevant physical examination were made to rule out any cardio pulmonary diseases. The height and weight of the subjects were recorded. Subjects with spinal 
deformity, history of smoking and cardio respiratory diseases were excluded from the study. The ethical committee clearance and an informed consent of the subjects were taken. The subjects were individually trained to measure their own PEFR records and one of them was chosen as a trained leader.

The test was carried out three times a day, morning 7 to $7.30 \mathrm{AM}$, afternoon 1 to $1.30 \mathrm{PM}$ \& evening 7 to $7.30 \mathrm{PM}$, each time three reading were taken and best of the three is taken for analysis. ${ }^{1}$

The pattern of PEF variability for each subject was noted and the range, mean and SD of PEF was calculated.

The PEFR values at different time points were analyzed by using one way analysis of variance (ANOVA).

Diurnal variation for individual subject was calculated by using two different indices amplitude percent mean (A\%M) i.e., difference between highest and lowest daily PEF reading as a percentage of the daily mean and standard deviation percent mean $(\mathrm{SD} \% \mathrm{M})$ as per the following formulae ${ }^{2}$

$$
\begin{aligned}
& \mathrm{A} \% \mathrm{M}=\frac{\text { Highest PEF }- \text { Lowest PEF }}{\text { Mean PEF }} \times 100 \\
& \mathrm{SD} \% \mathrm{M}=\frac{\text { SD of PEFvalues }}{\text { Mean PEF }} \times 100
\end{aligned}
$$

\section{RESULTS}

The age and anthropometric data of both the sex is shown in table 1 . The findings suggest that the two groups did-not differ significantly with respect to age and anthropometric parameters.

The mean \pm SD of PEFR recorded in morning, afternoon and evening in both the sexes is shown in table 2. Our results show that PEF in normal male subjects exhibits definite diurnal variation characterized by lowest values in the morning followed by progressive rise peaking in the evening. This was the commonest pattern observed with morning dip in 24 cases(\%) and evening rise in 26 subjects (\%). In females the PEFR rose in the afternoon and gradually falls in the evening. This pattern was observed with morning dip in 22 subjects (\%) and evening dip in 21 subjects (\%). The values of PEFR is higher in boys than in girls and it was statistically significant.

Distribution of amplitude as a percent of mean PEF is shown in Table 3. In the present study Mean diurnal variation was found to be7.00 \pm 4.46 $(\mathrm{A} \% \mathrm{M})$ and $3.65 \pm 2.35(\mathrm{SD} \% \mathrm{M})$, with $6.67 \pm 5.03$ $(\mathrm{A} \% \mathrm{M})$ and $3.50 \pm 2.73(\mathrm{SD} \% \mathrm{M})$ in males and $7.33 \pm 3.86(\mathrm{~A} \% \mathrm{M})$ and $3.80 \pm 1.94(\mathrm{SD} \% \mathrm{M})$ in females.There is no statistical significant difference in diurnal variation between males and females.

Table 1:SHOWING THE AGE AND ANTHROPOMETRIC DATA OF THE STUDY POPULATION

\begin{tabular}{|l|l|l|l|l|l|l|}
\hline \multirow{2}{*}{ PARAMETER } & \multicolumn{3}{|l|}{ MALE } & \multicolumn{2}{l|}{ FEMALE } & \multicolumn{2}{l|}{ TOTAL } \\
\cline { 2 - 7 } & Mean & \pm SD & Mean & \pm SD & Mean & \pm SD \\
\hline AGE $($ years $)$ & 18.96 & 1.16 & 19.12 & 1.17 & 19.04 & 1.17 \\
\hline HEIGHT $(\mathrm{cm})$ & 1.68 & 0.07 & 1.57 & 0.05 & 1.63 & 0.06 \\
\hline Weight $(\mathrm{Kg})$ & 59.51 & 9.69 & 57.20 & 10.22 & 59.5 & 9.96 \\
\hline BMI $\left(\mathrm{Kg} / \mathrm{m}^{2}\right)$ & 21.01 & 9.78 & 23.31 & 4.04 & 21 & 6.91 \\
\hline
\end{tabular}

\begin{tabular}{|c|c|c|c|c|c|c|c|}
\hline \multirow[t]{2}{*}{ PEFR } & \multicolumn{2}{|l|}{ MALE } & \multicolumn{2}{|c|}{ FEMALE } & \multicolumn{2}{|l|}{ TOTAL } & \multirow{2}{*}{$\begin{array}{l}\text { SIGNIFICANCE } \\
\text { (BETWEEN MALE } \\
\text { AND FEMALE) }\end{array}$} \\
\hline & MEAN & SD & MEAN & SD & MEAN & SD & \\
\hline MORNING 7 AM & 502.50 & \pm 54.90 & 406.67 & \pm 53.97 & 454.58 & \pm 72.44 & $<0.01$ \\
\hline NOON 12 NOON & 509.60 & \pm 60.51 & 425.00 & \pm 51.44 & 467.30 & \pm 70.14 & $<0.01$ \\
\hline EVENING 7PM & 530.63 & \pm 55.89 & 411.44 & \pm 53.82 & 471.34 & \pm 80.98 & $<0.01$ \\
\hline
\end{tabular}

Table 2: SHOWING PEFR IN MORNING, AFTERNOON AND EVENING. 
Table 3: SHOWING MEAN VARIATION OF PEFR

\begin{tabular}{|l|l|l|l|l|l|l|l|}
\hline \multirow{2}{*}{ PARAMETRE } & \multicolumn{2}{l|}{ MALE } & \multicolumn{2}{l|}{ FEMALE } & \multicolumn{2}{l|}{ TOTAL } & \multirow{2}{*}{ SIGNIFICANCE } \\
\cline { 2 - 7 } & MEAN & SD & MEAN & SD & MEAN & SD & M:F \\
\hline A\%M & 6.67 & \pm 5.03 & 7.33 & \pm 3.86 & 7.00 & \pm 4.46 & $>0.05$ \\
\hline SD\%M & 3.50 & \pm 2.73 & 3.80 & \pm 1.94 & 3.65 & \pm 2.35 & $>0.05$ \\
\hline
\end{tabular}

\section{DISCUSSION}

The study was conducted among the healthy young individual of the North Eastern region of India. The pattern of diurnal rhythm observed in the total population was that of a lowest value in the morning with gradual rise in the evening. Male showed a definite peak while female showed a fall at bedtime. Similiar variation was observed by various other authors like A.N Aggarwal et al ${ }^{3}$,Quackenboss JJ et al ${ }^{4}$,Casale R et $\mathrm{al}^{5}$,Zureik M et $\mathrm{al}^{6}$ and Goval $\mathrm{M}^{9}$.Our result indicated that there is no significant difference in diurnal variation of PEFR between both the sexes. This is in agreement of the studies by Hetzel MR et $\mathrm{al}^{7}$.

Diurnal variation expressed as $\mathrm{A} \% \mathrm{M}$ and $\mathrm{SD} \% \mathrm{M}$ in the present study are found to be similar with other Indian studies but found to be lower than that of Western studies ${ }^{4,8}$

\section{CONCLUSION}

We conclude that a diurnal variation pattern of PEF is seen in healthy population. Diurnal variation in peak expiratory flow is an important measurement in screening and diagnosis of asthma, as well as for assessing disease severity and prognosis

\section{REFERENCES}

1. American thoracic society. standardisation of spirometry:1994 update. Am J Respir Crit Care Med 1995;152:1107-1136

2. Higgins BG,Britton JR, Chinn S,et al.The distribution of peak expiratory flow variability in a population sample.Am Rev Respir Dis 1989;140:1368-1372

3. A.N.Aggarwal,D.Gupta,S.changanti and S.K Jindal, Diurnal variation of peak expiratory flow rate in healthy young adults. The Indian journal of Chest Disease and allied sciences, 2000, vol 42:15-19.

4. Quackenboss JJ,Lebowitz MDet al.The normal range of Diurnal changes in peak expiratory flow rate: Relationship to symptoms and respiratory disease Am Rev Respir Dis 1991;143:323-330

5. Casale R,Pasqualetti P.Cosinor analysis of circadian peak expiratory flow variability in normal subjects,passive smokers, heavy smokers, patients with chronic obstructive pulmonary disease and patients with interstitial lung disease.respiration 1997; 64:251-256

6. Zureik M,Liard R,Segala C,Henry C et al: peak expiratory flow variability in population survey: Does the number of assessment matter? Chest 1995,107:418423

7. Hetzel MR, Clark TJH. Comparison of normal and asthmatic circadian rhythm in peak expiratory flow rate.thorax 1980;35:732-738.

8. Higgins BG, Britton JR, Chinn S, Lai KK, Burney PG, Tattersfield AE. Factors affecting peak expiratory flow variability and bronchial reactivity in a random population sample. Thorax 1993; 48: 899905.

9. Goval M, Goel A, Kumar P, Bajpai M, Verma NS, Kant S, Tiwari S. Circadian rhythm of peak expiratory flow rates in healthy north Indian men. Indian J Physiol Pharmacol 2008;53:64-8. 